\title{
Cultural and Religious Beliefs and Practices Abusive to Children With Disabilities in Zimbabwe
}

\author{
A. T. Mukushi ${ }^{1}$, J. C. Makhubele ${ }^{1} \&$ V. Mabvurira ${ }^{1}$ \\ ${ }^{1}$ Department of Social Work, University of Limpopo, Sovenga, South Africa \\ Correspondence: J. C. Makhubele, Department of Social Work, University of Limpopo, Private Bag x 1106, \\ Sovenga, Polokwane, 0727, South Africa. E-mail: Jabulani.Makhubele@ul.ac.za
}

Received: January 29, 2019 Accepted: June 10, 2019 Online Published: June 11, 2019

doi:10.5539/gjhs.v11n7p103 URL: https://doi.org/10.5539/gjhs.v11n7p103

\begin{abstract}
This study sought to explore religious practices and beliefs that violate the rights of children with disabilities in Zimbabwe. The authors employed a qualitative approach in exploring cultural and religious beliefs and practices abusive to children with disabilities. Authors used exploratory-descriptive case study design and purposive sampling in selecting participants. Data collection took place in Dzivarasekwa, a high-density suburb in Harare among children who were receiving rehabilitation services at Harare Hospital and their caregivers. The study established that children with disabilities who come from some apostolic families are disadvantaged, as their parents believe that demonic spirits causes disability. This then leads to heightened levels of discrimination. The study also found out that there are remedial but harmful cultural and religious practices. The study recommends that rigorous awareness raising is needed for communities to support people with disabilities, formation of support groups amongst people with disabilities themselves, introducing holistic interventions that address issues of cultural and religious beliefs and continuous training for frontline workers to keep in touch with current best practices, policies and laws around disabilities.
\end{abstract}

Keywords: children, disability, caregiver, psychosocial challenges, religious, cultural, traditional

\section{Introduction}

There are many misconceptions and myths attached to disability in Zimbabwe. These are mainly expounded through religious and cultural lenses. An observation by Miles (2001) attests that disability in the Holy Bible, particularly in the book of Exodus is attributed to the sins of parents. In Africa, disability is generally attributed to witchcraft and such cultural and religious interpretations have a bearing on how children with disabilities are treated (Mukushi, 2018). The caregivers of children with disabilities bear much of the burden that children with disabilities face and as such, they are left with a plethora of challenges. In some cases, the parents violate the rights of children in trying to correct the disability using cultural or religious means. Given this situation in Zimbabwe, this paper aims on assessing the challenges that children with disabilities and their caregivers face in line with the cultural and religious beliefs surrounding disability.

\subsection{Literature Review}

Various schools of thought try to explain causes, management and other issues relating to disability. These different hypotheses known as approaches or models to disability, amongst them include the traditional/religious model, the social model, the charity model and the medical model, to mention the few (Mugumbate and Mtetwa, 2014). This paper focuses more on the traditional approach also referred to as the religious model of disability. This model views disability with religious or traditional lenses (Oliver, 1996). Similarly, explanations on the causes of disability are linked to traditional beliefs and religion, that is, the gods, ancestors, God or evil spirits (Mugumbate \& Mtetwa, 2014). Resultantly, this view influences the attitudes and treatment directed towards people with disabilities (Miles, 2006).

Indigenous knowledge systems and beliefs on the causes of disability are key in determining the attitudes of the society towards people with disabilities and disability in general (Miles, 2006). Most traditional beliefs consider disability to be a result of supernatural forces or incongruous deeds like incest (Haihambo and Lightfoot, 2010). Various scholars including Haihambo and Lightfoot (2010) and Mupedziswa (2005) reported that a majority of people in Africa believe that witchcraft, punishment from God, avenging spirits, or promiscuity on the part of one 
or both parents can cause disability. It is important to note that these traditional beliefs play a role on how communities support and respond to the needs of people with disabilities. In most families, disability leads to family schisms and division as family members level accusations of witchcraft or wrongdoing among each other (Finkenflugel, Maannen, \& Schut, 2016). Lack of acceptance for the condition of the child might also trigger stress related emotions, resultantly affecting the psychological state and social interactions of parents and this consequently affects the child (Finkenflugel et al., 2016).

Zimbabwe has two main belief systems: the indigenous African Traditional Religion (ATR) and other religious beliefs, which came due to colonisation like Christianity and Islam. In ATR, there is belief that there is God who is the creator and has the ultimate powers to life. There is also a belief that deceased family members create an invisible family (ancestors), who have an impact on the lives of the living (Moyo, 1988). Apart from believing that the dead have influence on the living, there is also a belief that there are other spirits like ngozi (avenging spirits) which wizards can converse with (Moyo, 1988). Likewise traditional healers ( $n$ 'angas) can converse with ancestors. Christianity which was brought in the country by European missionaries is the other biggest religious belief in the country, it constitute about $80 \%$ of the country`s population (Sosusa, 2018). It is however important to note that majority of Christians are still influenced and practice in part or in full ATR, for example most Christians believe avenging spirits are real.

Documentation and information regarding ATR in Zimbabwe and its influence on disability is very limited but the belief system associates misfortunes as a sign of angry ancestors, avenging spirits or attacks by either evil spirits or wizards (Moyo, 1988). It is in this regard that traditional societies in Zimbabwe view disability negatively. This negative interpretation of disability in African societies translate to the horrendous treatment given to people with disabilities by their communities. It also translate to harmful practices adopted by caregivers and families in trying to "correct" the situation.

For Christians who constitute the main religious group in Zimbabwe (Sosusa, 2018), there are mixed attitudes and perceptions towards disability (Mukushi, 2018). Miles (2006) speculates that Jesus, in the New Testament, said that disability is not punishment from God, but rather, an opportunity for God to demonstrate his power. However, Miles (2001) also notes that the same Bible in Exodus seems to present children with disabilities as suffering because of the wrong deeds of their parents. Leviticus 21 verse 16 to 23 also discriminate against people with disabilities. This creates divided perceptions towards people with disabilities and their families in the Christian community.

Miles (2006) argues that Christianity, Judaism and Islam do not seem to offer enough support for people with disabilities in as far as their day-to-day lives and real needs are concerned. These religions influence perceptions, attitudes and remedial and coping practices towards disability by both caregivers and the community members. Disability is considered as punishment from God and in some cases, the Bible discriminates people with disabilities as shown in Leviticus 21 verses 16 to 23, which clearly discriminate against people with disabilities (Finkenflugel et al., 2016). In line with the above-mentioned verses, disability is seen as a curse, and "believers" avoid associating and interacting with people with disabilities and their families. This, consequently, has huge implications to people with disabilities in general and to children in particular (Miles, 2006).

\subsection{The Rights of People with Disabilities in Zimbabwe}

Disability is a human rights reality and this has been the case for the past several decades as nations began to see that people with disabilities continue to be sidelined by society (Chambers and Chambers, 2016). The Second World War unequivocally inspired the realisation of disability as a human rights issue after a multitude of soldiers and civilians became disabled during the course of the war. As such, nations began to recognise the disabled as people who needed adequate care. It is however important to note that people with disabilities have for a long time been excluded, socially, economically and emotionally. According to Chambers and Chambers (2016), with the advent of the disability movement, there has been the development of disability policies and legislations for disability rights promotion.

Zimbabwe was one of the first countries to adopt disability related legislation through the promulgation of the Disabled Persons Act (DPA) of 1992 (Manatsa, 2015). This was a progressive development considering that for many years, people with disabilities were burdened by the absence of such pieces of legislation. The enactment of the DPA in 1992 widened the vistas of disability rights activism in Zimbabwe, with disability organizations advocating for equal opportunities for people with disabilities (PWDs) with their non-impaired counterparts (Chimedza \& Peters, 1999). The DPA is the major law that addresses disability in Zimbabwe and as noted by (Mwalimu, 2003) it prohibits discrimination against PWDs namely access to public premises, services, amenities and employment. The Act has, however, no formal policies, strategies and agreed standards to monitor its 
implementation (Manatsa, 2015). Another weakness is its silence in improving the general perceptions for communities towards people with disabilities.

In 2013, within the latest constitution in Zimbabwe (Constitution of Zimbabwe, Amendment No 20 Act of 2013), the government adopted a human rights approach to disability as for instance, discrimination against people with disabilities in now unconstitutional (Mandipa, 2013). Thus a strong foundation for safeguarding the rights of PWDs although it is a fact that these rights and traditional cultural perspectives exist side by side.

Zimbabwe ratified the United Nations Convection of the Rights of people with Disabilities in 2013. The government, in response to the Convention has put in place a number of provisions for PWDs and a lot of strides have been taken by civil society actors (Mukushi, 2018). Nevertheless, children with disabilities still find themselves deprived several unpardonable rights like the right to education, health, justice amongst others. In the latest constitution of Zimbabwe, (Constitution of Zimbabwe, Amendment No 20 Act of 2013), everyone has a right to education and this enables them to take part effectively in a free society. The Education Act and the Disabled Persons Act also put education as a right for everyone. However, without deliberate measures taken for proper implementation, the pieces of law will not result in children with disabilities accessing relevant services as provided for in these legislations (Manatsa, 2015). Despite the legislations in place, the physical environment in some schools is not disability-friendly; children with wheelchairs cannot access classrooms. Mukushi (2018) argues there is a pronounced shortage of specialised teachers at schools and the caregivers of children, many at times have to bear the burden of huge educational expenses towards the education of the children despite that majority of them come from economically deprived families.

\subsection{Discrimination}

As highlighted above, most communities attribute disability to witchcraft, avenging spirits, punishment from God and ancestors and or an evil force. According to James and Fleischer (2001), communities that believe there is someone to blame within the family of a child with a disability do not wish to associate themselves with the family, they believe they will end up being contaminated. Children with disabilities are discriminated against right from birth. In a study conducted by Nimbalkar, Raithatha, Shah and Panchal (2014) in India, parents of children with disabilities testified that kinsfolks made many disparaging remarks about their disabled children and they found this to be very disturbing. This, as argued by Nimbalkar et al. (2014), is a form of emotional abuse to both the children and caregivers. At times, they felt that very few people supported them and that society as a whole was against them. They narrated experiences in which they experienced neglect from society due to the attitudes and beliefs that society holds on disability.

It is important however to note that discrimination happens at different levels. As observed by Willacy (2012), disability is a family experience and this means that the family is the first and primary support system for both the child and the caregiver who is usually the mother or the grandmother of the child. However, at family level discrimination starts (Nimbalkar et al., 2014). Discrimination also takes place at community level whereby community members disassociates themselves with the immediate family of a child with a disability. It can also happens at institutional level. Yeo (2011) argues that discrimination starts at birth throughout the life of a person with a disability. Some public institutions are not disability friendly (Mukushi, 2018). The personnel manning the institutions are not capacitated enough to accommodate PWD in most cases.

\section{Methodological Approach}

A qualitative approach was used and the researchers opted for a case study design. A qualitative approach was chosen because of its ability to explore, in depth, the cultural and religious practices harmful to children with disabilities. The authors felt that the challenges that are experienced by children with disabilities due to culture and religion warrant a thorough investigation, hence the need for an in-depth understanding of those cultural and religious practices. The research had two main subject groups, children with disabilities and their caregivers. Children chosen ranged from ten to seventeen years of age. In selecting a sample, the researchers used purposive sampling, which is a non-probability sampling technique. Selected were fifteen children with disabilities together with 10 caregivers. Even though this frequently applies to quantitative research, the researchers made use of the rule in order to have a sample that ensures trustworthiness of the data. The participants were drawn from clients of Rehabilitation Unit (Harare Hospital) who resided in Dzivarasekwa, a high-density suburb in Harare.

The researchers used interview guides and focus group discussion guides to collect data. According to Yates (2004), in-depth interviews are subjective dialogues between the researchers and the participants for the sole reason of acquiring information from the latter. A focus group discussion was used to collect data, Walliman and Appleton (2009) describe focus group discussions (FGD) as sets of people who discuss particular topics in 
research with the guidance of the researchers. A FGD was used because it stimulates richer responses as participants motivate others to open up. Researchers sensitised the participants of the research and of all ethical issues involved. Both the interviews and FGD were not voice recorded; information recorded by way of writing notes.

The researchers used thematic content analysis to analyse the data. According to Bhattacherjee (2012) and Punch (2005), data analysis is about working with data, grouping it, breaking it into manageable units, searching for patterns, discovering what is important and what is to be learned, and deciding what needs to be revealed to others. The Interview transcripts and field notes were systematically arranged into themes for interpretation and analysis. Data from both interviews and FGD were grouped according to themes.

\subsection{The Limitations of the Study}

This section discusses characteristics of the methodologies that affected and influenced interpretation of findings. It discusses issues that constraints generalizability of the study. The study was conducted in one high-density suburb and therefore it may be difficult to generalise the findings to other areas. There is also a critical shortage of recent and relevant literature on disability in general and disability and religion in Zimbabwe. The sample size might also be too small to generalise for the whole of Zimbabwe especially considering that participants were drawn from a single high-density suburb.

\section{Findings and Discussion}

\subsection{Religious Beliefs of Caregivers}

\subsubsection{Apostolic Churches}

Most apostolic churches in Zimbabwe are African initiated Christian churches. They have different names and leaders but the belief system is almost the same. In as much as they believe in the Bible they also borrow from the African Traditional Religion. As a result, participants who were Apostolic almost shared the same beliefs with those who believed in ATR. Seven out of the ten caregivers were members of apostolic churches.

There are a number of remedial practices caregivers highlighted in response to children's condition. Every apostolic member believed in the prophet praying for water, which the child with a disability can drink, bath with or used to spray in the homestead to get rid of evil spirits, which cause disability. One caregiver said.

"The prophet prays for small stones and water, which we can use on the child either to drink as medicine or bath with. Sometimes we spray the water in our house and compound to get rid of the evil spirits, which cause mental problems on the child."

The above narrative from one caregiver seem to concur with Haihambo and Lightfoot (2010) who argue that disability in most cases is seen as caused by avenging spirits or evil spirits. It is this belief then, which guides caregivers to put much of their focus on finding a spiritually related solution. In stressing this point, another caregiver said:

"Because we know that disability do not just come unless there is foul play we try to fight with prayers and help from prophets. The strings we tie on children's hands are meant to protect them against evil spirits, they are spiritual protection".

\subsubsection{Mainstream and Pentecostal Churches}

Mainstream and Pentecostal churches are those Christian gatherings that were introduced to Zimbabwe through European missionaries who came to the country. They can be traced from the holiness movement of the Methodist church to now the modern Christianity they have become (Makamure, n.d.). Pentecostal life emphasizes accepting Jesus as the Lord and personal saviour as well as gifts such as speaking in tongues as well as divine healing. Ideally, the beliefs of these churches are not influenced by African traditional culture. However, participants from these churches were found to believe in some aspects found in the African Traditional Religion, for example, avenging spirits' ability to cause misfortunes to people. Like the Apostolic churches, Pentecostal churches also believe in faith healing. One caregiver had this to say:

"Pastor usually says even if you are prayed for without the right mental attitude nothing will come but if you are prayed for with the right mental attitude even disability can be healed because everything is possible with Jesus"

Similar to the apostolic beliefs of the prophet praying for water, pastors in Pentecostal churches pray for oil, which is often called anointed oil and is, used for the same purposes as water in apostolic churches. One child said.

"Every time my grandmother goes to church, she buy anointing oil that she then use to apply on my legs saying it casts out evil spirits but it is not helping me at all" 


\subsection{African Traditional Religion}

African Traditional Religion is the indigenous traditional religion in Zimbabwe. No participant were affiliated hundred percent to the religion but all of the participants highlighted that although they are Christians it is difficult to completely disassociate themselves with ATR. Majority even highlighted that when family problems arise they visit traditional healers despite being Christian. It is therefore safe to argue that ATR is like the shadow of Zimbabwean people, despite believing Christianity, some aspects of the traditional religion still influence their day-to-day living.

\subsection{Beliefs on the Causes of Disability}

As established already there are two main belief systems in Zimbabwe, namely the ATR and Christianity. From both the indigenous traditional belief and Christianity, there is agreement on the causes of disability. All caregivers believed that there are certainly certain types of disabilities that are caused by supernatural forces. Widely held views were that disability might be caused by avenging spirits, witchcraft and or punishment from either God or the ancestors. Caregivers also had a widely held perception that discrimination of people with disabilities in general emanates from the perceived causes, as propounded by (Miles, 2006), as people do not want to associate with witchcraft, avenging spirits or punishment from God or ancestors.

The religious perspective holds disability as something that is a result of punishment from God for sins one committed together with witchcraft and evil forces. Majority of participants simply said, "It is the will of God". It is important to note however that these beliefs about the causes of disability are the basis of how communities treats people with disabilities together with their families (Miles, 2006). Caregivers who said it is the will of God were a bit reluctant to seek medical and rehabilitation services for their children, instead they sought faith healing.

It is however important to note that a minority of the participants highlighted that disability may be caused by accidents; prenatal health issues on the mother as well as genetic factors. Whilst they had this view, they also believed that supernatural forces still cause some types of disabilities. Needless to emphasize therefore, is the strongly held belief about the relationship between disability and supernatural forces. The country`s traditional and religious belief system associate disability with supernatural forces.

\subsection{Discrimination at Family and Community Level}

Similar to Nimbalkar et al (2014) 's observation participants highlighted that some people s avoid close interaction with the immediate family members of children with disabilities. Caregivers reported that they were not invited to most social gatherings and in those few incidences they are invited, the treatment they received clearly showed that they are not appreciated. One caregiver said:

"People think if they come near disabled children, they will be infected. Disability in is considered as punishment from God or from the ancestors, so people do not want to show sympathy, as they believe the disability is well-deserved..."

The caregivers highlighted that of all the challenges they are facing, discrimination was the most grievous challenge. This discrimination triggers a lot of emotional suffering for the caregivers and children, as it is a constant reminder of their burden. One caregiver said the following as she was becoming emotional:

"When you are carrying a child with disability even people who know you and the child keep staring at you like they do not know you, like you are carrying faeces..."

From the above account, it is noteworthy that caregivers of children with disabilities feel inferior and ashamed in their communities mainly because of the treatment they receive. This limits caregivers` participation in social events and it affects the quality of care the child resultantly gets.

\subsection{Discrimination at Institutional Level}

Caregivers were in consensus that even medical staff like nurses started treating them differently the moment they realised the "abnormality" of the child. They attributed this to the general community perception on disability. Caregivers went on to say that when they compare the friendliness before the delivery of the child and after, and comparing how nurses related to them and to other mothers of children with disabilities, they could see the harsh reality of discrimination against people with disabilities. This is similar to the observations made by Yeo (2001) that children with disabilities are discriminated against from birth, and this goes on for a lifetime. One caregiver said:

"When I went to labour, nurses were very friendly to me because I was young and smartly dressed. When I gave birth, they started distancing themselves from me because from birth my child resembled signs of disability. His 
head was too big"

Apart from discrimination at medical facilities, discrimination also comes from institutions like schools. Caregivers highlighted that children are often denied entry and access to schools, with authorities citing that their schools do not have facilities suitable for children with cerebral palsy, for instance. This is contrary to the government policy of inclusive education as argued by Mukushi, (2018). In explaining how discrimination at institutional level happens, one caregiver said:

"I once visited the school where my other children are learning with the intention of enrolling my child with cerebral palsy at that school. The headmaster said they could not enrol my child because this school has no facilities for children like these"

Whilst the above account is pointing out that government officials, seem to deny children with disabilities services enshrined in the constitution as their rights it is important to note that indeed the facilities do not cater for some disabilities. For instance, as noted by Mukushi, (2018) most government institutions (schools, district offices, etc.) are not disability friendly, they do not have ramps for wheel chairs and the toilets are not built to disability specifications. A combination of these system shortfalls and the traditional and religious perceptions influencing officials operating in institutions, children with disabilities often find themselves continuously struggling to access services.

\subsection{Harmful Cultural Practices}

Participants highlighted that there are some traditional remedies meant to end the disability. This is similar to an observation by Haihambo and Lightfoot (2010) that disabilities in most instances are interpreted culturally and likewise the solutions are found within the cultural spectrum. It is important however to note that even if the idea behind the traditional remedy is done with goodwill, it is a risk to the child's health considering hygienic issues and complications that may results from taking the remedy in its concentrated form.

The traditional ways of therapy include dipping the child in cold water or in a water source for some time, applying traditional medicines and consulting traditional healers. While participants claimed in some instances it had worked, it is important not to ignore the risk and dangers it poses to children. Children are at risk of waterborne diseases and drowning, overdose of traditional medicines and infections. This however is testimony to the fact that traditional and cultural beliefs pose a risk to children with disabilities, mainly because they cannot make their own choices regarding how they want to seek help and services, instead the community and parental beliefs are key.

\subsection{Support Systems}

Support systems are individuals and entities that offer emotional, physical, mental and spiritual support to caregivers and children with disabilities. Societies and communities have systems that support caregivers. These support systems come in many forms like non-formal, for example, family and friends and formal for example, professional rehabilitation programs by government and its partners.

As highlighted above, many caregivers agreed that the most important source of support comes from the immediate family of the child with a disability and the children themselves admitted this. Close relatives and friends distance themselves the moment they realise that there is a child with a disability in the family. In narrating how the family is the strongest support system, one caregiver said:

"It is difficult to have a child with disability. This is especially so when relatives clearly show they do not want anything to do with the child. Most of the times I get comfort from my immediate family. I can cry to my immediate family and they give me the strength to keep going..."

The caregivers highlighted that they receive donations, stipends and handouts, advice and social support from other members of society and various organisations. The church also emerged as another source of support for caregivers of children with disabilities. However, caregivers seemed to have divided notions towards how helpful the social support that comes from churches really is to them. Psychologically, they all believed the church is instrumental in that part especially from teachings and counselling from pastors and elders. Socially, the case was not the same. Caregivers highlighted that the same people who segregate against them in communities are the same people who come in church uniforms.

\subsection{Coping Strategies}

Caregivers have employed different coping mechanisms in an effort to curb the challenges they are facing. It is however, important to note that religious and cultural belief systems of the caregiver influence the coping mechanisms as propounded by (Miles, 2006). 


\subsection{Counselling}

Counselling give caregivers a different view of disability as well as acceptance to having a child with a disability. A young caregiver said:

"When I first noticed my child had cerebral palsy I couldn't accept it and thoughts of running away abandoning the child were frequent. When I started receiving counselling this quickly changed, now I accept that I have a child with a disability and whenever I feel troubled about the situation I seek counselling"

\subsection{Avoiding Intimidating Environments}

Caregivers have resolved to avoid intimidating environments. Respondents agreed that they avoid areas and places where they receive silly comments from strangers and members of extended families. A mother caregiver said:

"When I realised that my husband 's relatives were not comfortable around my child, I stopped visiting them at al."

Another caregiver also indicated that she has stopped going to places where there is intimidation. She said:

"I realised that when there is a gathering that is where people begin to talk from your back. I usually fetch water from the borehole when there are not many people there. I do not like family gatherings because the treatment I get is different from the one my age mates receive"

Caregivers agreed that they had to stop visiting members of the extended family, avoid going to public places during busy days, and generally cut themselves out of the entire social life of the community. However, avoiding emotional suffering by avoiding provocative comments also affects children with disabilities, as they grow up lonely and being "the cause" of family shame. This supports Chitereka's (2010) observation that disability in general is associated with shame and sin.

\subsection{Seeking Faith Healing}

The majority of caregivers believe that their children are in the condition they are because of witchcraft and supernatural forces as highlighted before. Because of this belief, caregivers have joined the apostolic sect or Pentecostal churches, hoping to use the prophetic power to cure their children. This supports the observation by Chitereka (2010) that disability generally is religiously interpreted. Whilst this interpretation has its own effects (Miles, 2006), joining the apostolic sect in search of cure is also dangerous to the child. Some caregivers confidently said that they do not adhere to prescriptions and advice from medical staff because of their apostolic beliefs. This endangers the child as withdrawal from daily routines that are medically proven may worsen the disability. A grandmother caregiver said:

"Some of the times what we are told at CRU is different from what we would have been told by God's Messenger."

Another caregiver (a young mother) also indicated that she went to the apostolic sector because of the child. She said:

"I grew up going to the Roman Catholic Church. When I gave birth, people were advising me to go to the apostolic sect; I ended up being a full time member of the sect. Most of the times we are given holy stones for protection and this really helps us..."

\subsection{Locking up Children in Houses}

Caregivers highlighted that the financial statuses of families of children with disabilities act a major barrier to quality caregiving for their children. It is, however, disheartening to note that in trying to curb this challenge, caregivers have, in a number of ways, abused their children and exposed them to serious emotional and behavioural threats. Children with disabilities have many limitations that can result in requirements for long-term care that far exceed the usual needs of children without disabilities (Nimbalkaret al., 2011). This observation is correct because the findings of this study suggest that one of the care requirements of children with disability is constant watch. However, caregivers are not able to provide this much-needed constant watch to their children. Every caregiver has other economic activities that they engage in so that they can feed the child. One caregiver said:

"I realised that when I am selling at my small market people would stop buying from me when they see a child with a disability. I then resorted to locking the child home so that I can sell"

Similar to the above narrative another caregiver said:

"I have a small vegetable market. During my first days, I would leave my child with my next-door neighbour. I would find my child unclean. Even when he soiled himself, I would find him like that, and all the time, I would find him lying down uncomfortably. I then realised that it was better to leave him home since he was not getting any 


\section{help from the neighbours"}

\subsection{Abandoning Family}

Disability is associated with negativity in many societies as already established. As a result, some caregivers resort to running away, abandoning their families altogether. Willacy (2012) argues that disability is a family experience. Some family members who cannot cope with the pressure resort to running away. The participants highlighted that either husbands abandoned them, or they experienced marital problems because of criticisms from family members as well as the financial needs required for children to survive. All the grandmother caregivers who participated indicated that the biological mothers of the children had abandoned them, leaving them in their care. A mother caregiver said:

"My husband abandoned me when he realised I gave birth to a child with disabilities. Even myself I once attempted to leave the child with her father's parents and run to South Africa. This, however, changed when I received counselling from $C R U$..."

The same view was also emphasised by a grandmother caregiver who said that she is taking care of the child because the biological mother ran away. She said:

"I am staying with my grandchild because the mother ran away; I do not even know where she is right now. At least she did not kill the baby. However, I take care of every need of this child without the help of the mother. She feared the disability and ran away..."

\section{Conclusions}

The research concludes that one of the major challenges caregivers of children with disabilities are facing is discrimination. Lack of acceptance of disability as an inevitable and natural occurrence by community members cause discrimination. Evidence suggests that the religious and cultural beliefs on the causes of disability influence discrimination. Disability is associated with spiritual or supernatural forces hence the treatment of people with disabilities in general is also guided by religion and traditional beliefs. Their religious and traditional understanding of disability also influences coping mechanisms caregivers of children with disabilities employ.

\section{Recommendations}

To lessen the effects of different religious and cultural practices and beliefs there should be efforts from the government, NGOs, the churches and communities in redefining disability and in adopting the medical model of disability. There is need to conduct awareness raising campaigns in communities on disability. The aim should be on making the community appreciate different pre-natal, natal and post-natal causes of disabilities. It is also important to raise awareness on available services at government institutions like health institutions and social welfare organisations. A deep understanding of different disabilities and how they are managed will go a long way in shifting perceptions and beliefs towards disability and hence improve the manner in which children with disabilities are treated. It has been observed that current programmes are mainly concerned with the rehabilitation of the child. The caregivers and families are left out in these. However, the wellbeing of the caregiver is directly related to the quality of support they provide to children. Strategies like organizing counselling sessions for the caregivers and parents, and capacity building workshops on disability for caregivers could be useful. It is also necessary to create a system that allows and encourages continuous professional development for the frontline service providers so that they keep up to date with new policies and new practices and that they continually develop and sharpen their expertise, thus improving the provision of care for children with disabilities.

\subsection{Areas for Further Research}

The research observed that there is pintsized literature regarding disability in Zimbabwe. Most conducted studies are on an international scale. This research therefore recommends that there be research initiatives that look into disability issues in Zimbabwe, particularly on improving welfare of people with disabilities. The Link between indigenous understanding of disability and the medical model is also a key study area in improving disability response in Zimbabwe.

\section{Competing Interests Statement}

The authors declare that there are no competing or potential conflicts of interest.

\section{References}

Ambikile, J., \& Outwater, A. (2012). Challenges of caring for children with mental disorders: Experiences and views of caregivers attending outpatient clinic at Muhimbili National Hospital, Tanzania. https://doi.org/10.1186/1753-2000-6-16 
Amelda, T., \& Sampaio, F. (2007). Stress and Social Support in Caregivers of individuals with Cerebral palsy. Columbia: Saude and Doencas.

Chambers, H. G., \& Chambers, J. A. (2016). Effects of caregiving on the families of childrenand adults with disabilities. California: University of California.

Chitereka, C. (2010). People with Disabilities and the Role of Social Workers in Lesotho: Maseru, National University of Lesotho.

Davies, D., \& Dodd, J. (2002). Qualitative research and the question of rigor. Qualitative Health research, 12(2), 279-289. https://doi.org/10.1177/104973230201200211

Finkenflugel, H., Maannen, V., \& Schut, W. (2016). Appreciation of community based rehabilitation by caregivers of children with a disability. Disability and Rehabilitation, 18, 255-260. https://doi.org/10.3109/09638289609166310

Golafshani, N. (2003). Understanding Reliability and Validity in Qualitative Research. The Qualitative Report, 8(4), 597-606. Retrieved from https://nsuworks.nova.edu/tqr/vol8/iss4/6

Haihambo, C., \& Lightfoot, E. (2010). Cultural beliefs regarding people with disabilities in Namibia: implications for the inclusion of people with disabilities. International Journal of Special Education, 25(3), 2010.

James, T., \& Fleischer, F. (2001). The Disability Rights Movement: From Charity to Confrontation. Philadelphia: Temple University Press.

Makamure, C. (n.d.). RELIGION AND DISABILITY: A reflection on the role of pentecostal churches in curbing marginalisation of People with Disability in Zimbabwe. Retrived from https://www.academia.edu/37604229/

Mandipa, E. (2013). African Disability Yearbook (Vol. 1). Pretoria University Law Press: Pretoria.

Miles, M. (2006). Martin Luther and Childhood Disability in 16th century Germany. What did he write? What did he say? Journal of Religion, Disability and Health, 5(4), 5-36. https://doi.org/10.1300/J095v05n04_02

Moyo, A. (1988), Religion and Political Thought in Independent Zimbabwe, in C. Hallencreutz and A. Moyo (1988) Church and State in Zimbabwe. Gweru: Mambo Press.

Mugumbate, J., \& Mtetwa. (2014). Promoting Social Work for Zimbabwe's Development: People with disabilities in Zimbabwe. Bindura: Bindura University Press.

Mukushi, A. T. (2018). Psychosocial Challenges Faced by Caregivers of Children with Cerebral Palsy in Dzivarasekwa Suburb, Harare, Zimbabwe: Implications for Social Work Practice (MSW Dissertation submitted to the University of Limpopo, South Africa (unpublished)).

Mupedziswa, R. (2005). Challenges and prospects of Social Work services in Africa. In J. C. Akeibunor and E. E. Anugwom (Eds), the social science and socio-economic transformation in African (pp.271-317), Nsukka: Great A. P Express Publishing.

Oliver, M. (1996). Understanding disability: From theory to practice. MacMillan, Basingstoke.

Patton, M. Q. (2002). Qualitative evaluation and research methods (3rd ed.). Thousand Oaks, CA: Sage Publications, Inc.

Stenbacka, C. (2001). Qualitative research requires quality concepts of its own. Management Decision, 39(7), 551-555. https://doi.org/10.1108/EUM0000000005801

Walliman, N., \& Appleton, J. (2009). Your Undergraduate Dissertation in Health and Social Care. London: Sage Publications. https://doi.org/10.4135/9781446202449

\section{Copyrights}

Copyright for this article is retained by the author(s), with first publication rights granted to the journal.

This is an open-access article distributed under the terms and conditions of the Creative Commons Attribution license (http://creativecommons.org/licenses/by/4.0/). 